\title{
Bilateral elastofibroma dorsi
}

\author{
İstemi YÜCEL (*), Kazım SOLAK (**), Mehmet ARICAN (**), Kutay Engin ÖZTURAN (***)
}

\section{ÖZET}

Elastofibroma dorsi, siklıkla göğüs duvarının subskapular bölgesinde görülen, kapsülsüz olduğu için sinırlart iyi ayırt edilemeyen, nadir görülen, fibröz dokudan kaynaklanıp yavas büyüme eğiliminde olan yumuşak doku tümörüdür. Etyolojisi tam olarak tanımlanamamıştır. Sıklıkla skapulanın alt köşesinde latissimus dorsi ile serratus anterior kasları arasinda, toraks duvarının periostuna yapışı olarak bulunur.

Bu çalıșmada, klinik yakınmaları olan ve cerrahi tedavi uyguladı̆̆ımız bilateral elastofibroma dorsi tanısı alan bir hasta sunulmuştur.

Anahtar kelimeler: Bilateral elastofibroma dorsi, skapula, sirt ăgrtst

\section{SUMMARY}

Bilateral elastofibroma dorsi: A case report

Elastofibroma dorsi, a rare soft tissue tumor often seen in the subscapular chest wall, is unencapsulated with indistinguishable borders, and originates from fibrous tissue and tends to grow slowly. Its etiology is not identified fully. It is commonly seen on the inferior corner of the scapula adherent to the chest wall between latissimus dorsi and serratus anterior muscles.

In this study a case of bilateral elastofibroma dorsi in a female patient which was treated surgically is presented.

Key words: Bilateral elastofibroma dorsi, scapula, back pain

arasında bildirilmiştir (12). Çoğunlukla 50 yaş üzeri kadın hastalarda tek taraflı olarak karşımıza çıksa da, \% 10 oranında her iki tarafta da görülebilir ${ }^{(10)}$.

Etiyolojisi tam olarak tanımlanamamışırır (2). Yinelenen travmalar sonrası gögüs duvarı ile skapula arasında oluşan mekanik sürtünme sonucu oluşabileceği bildirilmiştir (3). Hastaların yarısında klinik yakınmaya yol açmayabilir. Genel olarak şişlik, sırt ve omuz ağrısı, sırtta atlama sesi gibi yakınmalara yol açar ${ }^{(4,8,13)}$. Beş santimetreden büyük ağrilı şişlikler malignite şüphesi yaratabilir $(2,5)$. Tanı için dikkatli bir radyolojik değerlendirme yeterli olsa da malignitenin dışlanması açısından biyopsi yapılmasını öneren çalışmalar da vardır (2,4,5,9,14-16). Elastofibroma dorsinin tanı ve tedavisi ile ilgili çok az klinik çalışma bulunmakta ve tartışmalar sürmektedir.

Otopsi çalışmalarında görülme oranı $\% 13$ ile $\% 17$

Geliş tarihi: 05.04 .2012

Kabul tarihi: 11.05.2012

Düzce Üniversitesi Tıp Fakültesi, Ortopedi ve Travmatoloji Anabilim Dalı, Doç. Dr.*; Araş. Görev.**; Abant İzzet Baysal Üniversitesi, İzzet Baysal Tıp Fakültesi, Ortopedi ve Travmatoloji Anabilim Dalı, Yrd. Doç. Dr.*** 
$\mathrm{Bu}$ çalışmada, klinik yakınmaları olan ve cerrahi tedavi uyguladı̆̆ımız bilateral elastofibroma dorsi tanısı alan bir hasta sunulmuştur.

\section{OLGU SUNUMU}

Elli beş yaşında kadın hasta, uzun zamandır mevcut olan, özellikle son altı ayda artan her iki skapula bölgesinde, omuz hareketleriyle başlayan, sırta vuran ağrı yakınmasıyla başvurdu. Fizik muayenede her iki skapula inferomedialinde hareketli, yarı sert, palpasyonda hassasiyeti olmayan, ağrılı, omuz hareketiyle belirginleşen kitleler tespit edildi (Şekil 1). Rutin laboratuvar inceleme değerleri normal sinırlardaydı. Manyetik rezonans incelemede her

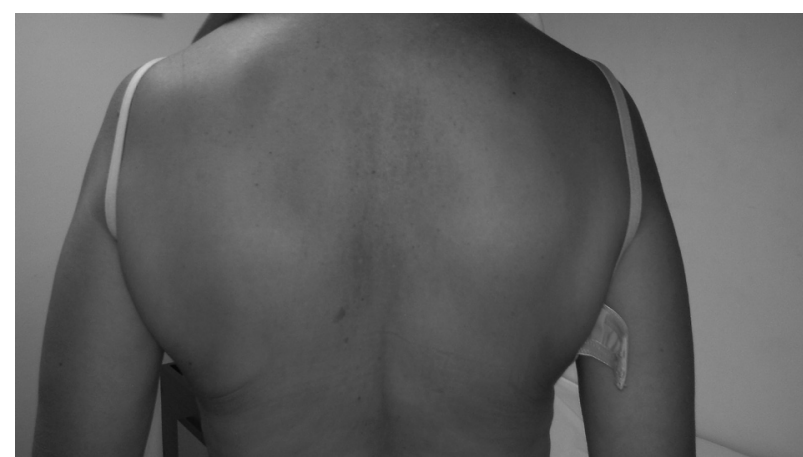

Şekil 1. Her iki skapula alt köşesinde elastofibroma dorsinin görünümü.

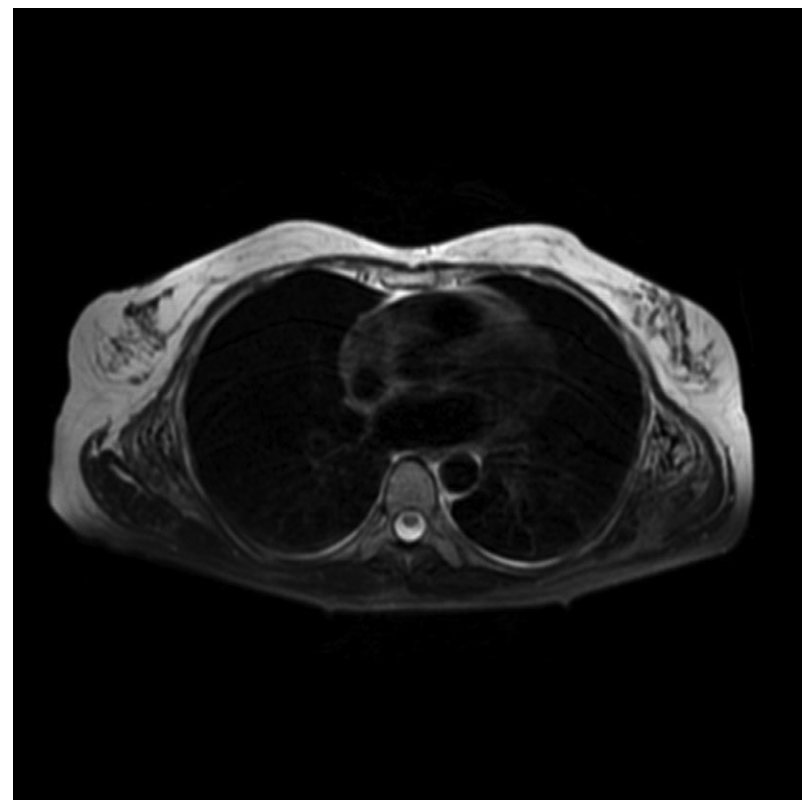

Şekil 2a. İki taraflı elastofibroma dorsinin T2-ağırlıklı transvers kesit manyetik rezonans göruntüsü. iki subskapular bölgede, skapula tepesinin inferiorunda, latissimus dorsi kası komşuluğunda solda $165 \times 90 \mathrm{~mm}$ boyutunda, sağda $86 \times 45 \mathrm{~mm}$ boyutunda lobüle konturlu kas ile izointens, içerisinde körvilineer ve lineer hiperintens alanlar içeren hafif çevresel kontrast tutan ve çevresel anatomik yapılarda belirgin invazyon göstermeyen lezyonlar izlendi (Şekil 2a, 2b, 2c).

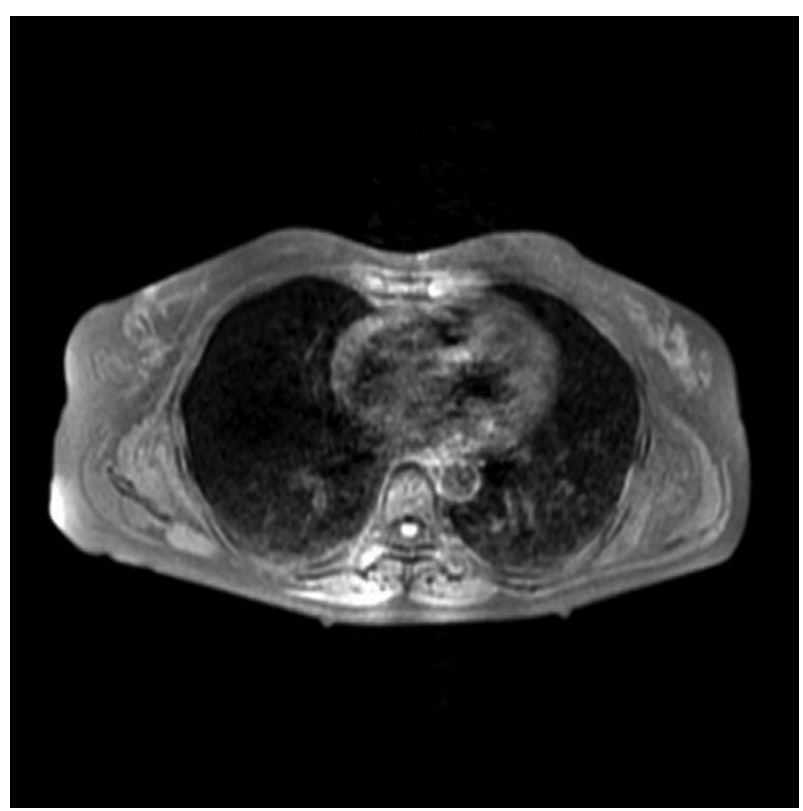

Şekil 2b. İki taraflı elastofibroma dorsinin T1-ağırlıklı transvers kesit manyetik rezonans görüntusü.

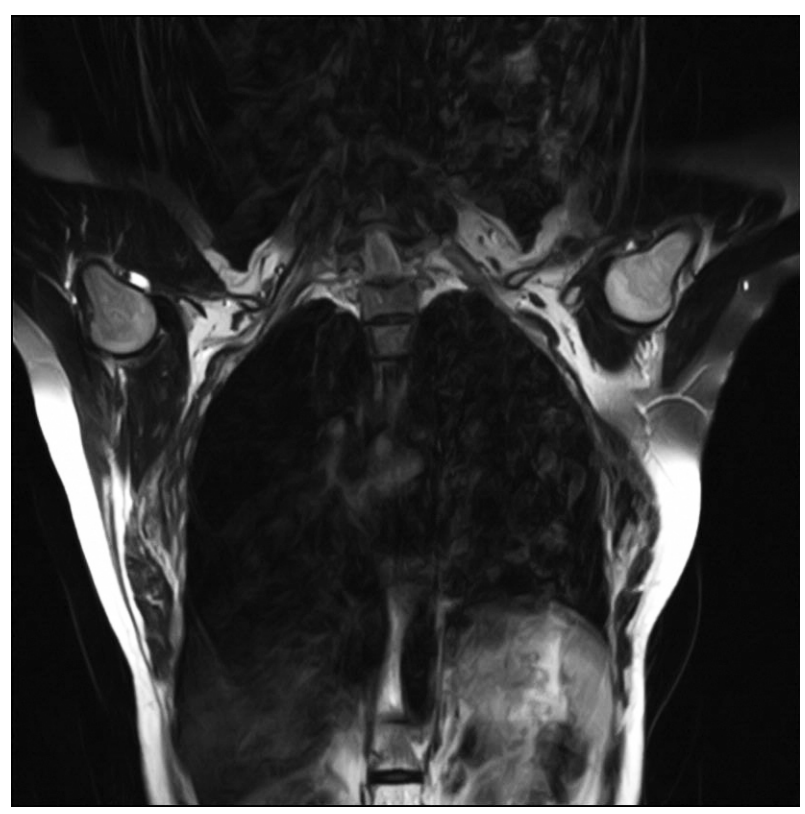

Şekil 2c. İki taraflı elastofibroma dorsinin T2-ağırlıklı koronal kesit manyetik rezonans görüntusü. 
Hastaya cerrahi tedavi planlandi. Genel anestezi altında, prone pozisyonda hastanın her iki skapula posteriorundan $10 \mathrm{~cm}$ 'lik longitudinal oblik insizyonlarla girildi. Latissimus dorsi kasi, liflerine paralel olarak açılarak kitlelere ulaşıldı. Lastik kıvamında, hareketli, beyaz, solda yaklaşık 170x100 mm (Şekil 3a), sağda yaklaşık 90x50 mm (Şekil 3b) boyutunda kitleler, göğüs duvarına sikı olarak tutunmuştu ve skapulanın altına doğru uzanıyordu. Kitlelere marjinal eksizyon uygulandı. Patolojik incelemede makroskobik olarak, üzeri yer yer fibröz kapsülle örtülü ve yer yer yağ dokusu içeren, kesit yüzeyi sarı beyaz renkteki solid lezyonlar belirlendi. Hematoksilen-eozin kesitlerin mikroskopik incelemesinde, matür adipositler ve fibrokollagen doku içerisinde dejenere, elatik Von Gieson özel boyasıyla pozitif boyanan elastik fib-

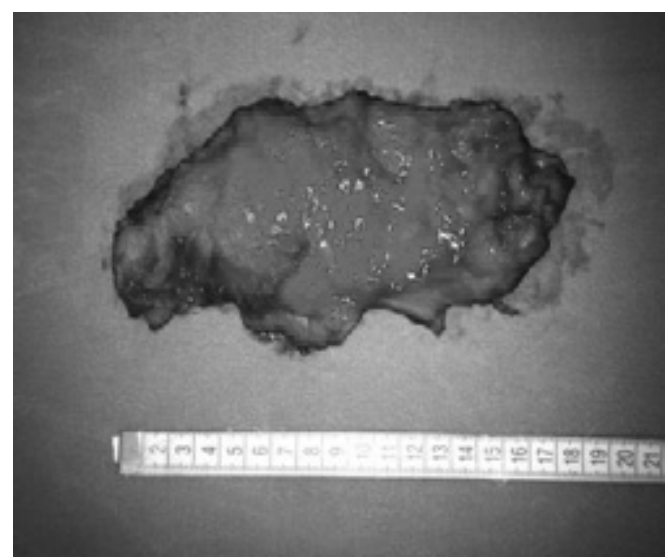

Şekil 3a. Sol skapuladan eksize edilen üzeri yer yer fibröz kapsülle örtülü ve yer yer yağ dokusu içeren lastik kıvamında yaklaşı 170x100 mm lik elastofibromanın makroskopik görünümü.

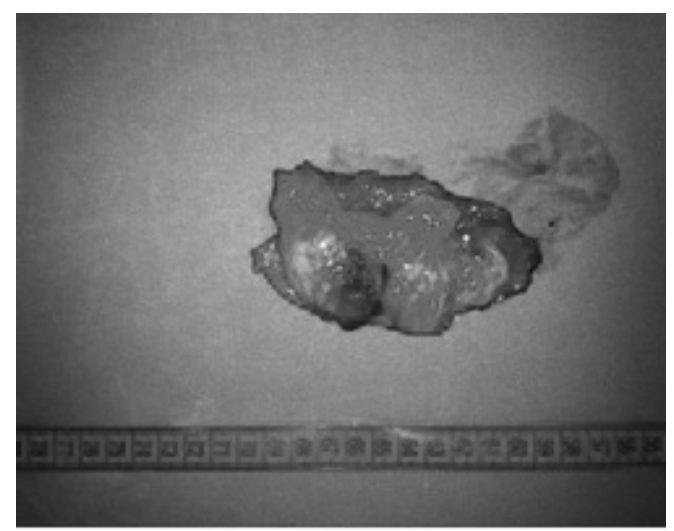

Sekil 3b. Sağ skapuladan eksize edilen üzeri yer yer fibröz kapsülle örtülï ve yer yer yağ dokusu içeren lastik kıvamında yaklaşık 90x50 mm lik elastofibromanın makroskopik görünümüi. riller görüldü (Şekil 4a, 4b). Ameliyat sonrası komplikasyon gelişmedi ve hastanın birinci ay kontrolünde yakınmalarının azaldığı tespit edildi.

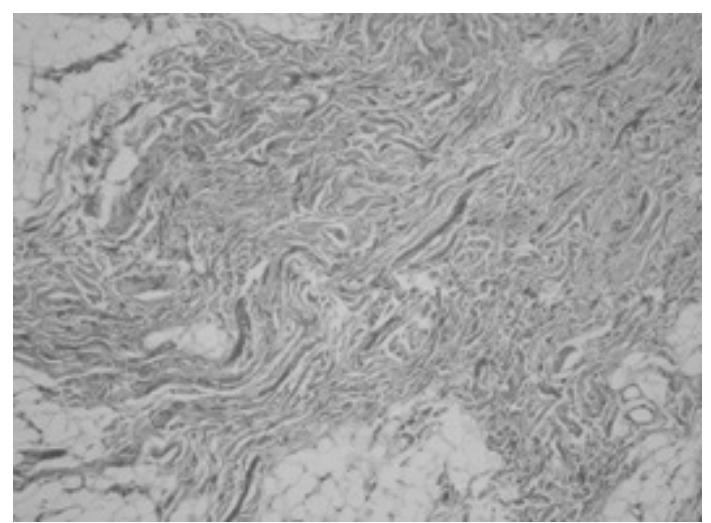

Şekil 4a. Hematoksilen-eozin kesitlerin mikroskobik incelemesinde matür adipositler ve fibrokollagen doku içerisinde dejenere elastik fibriller (H\&E x100).

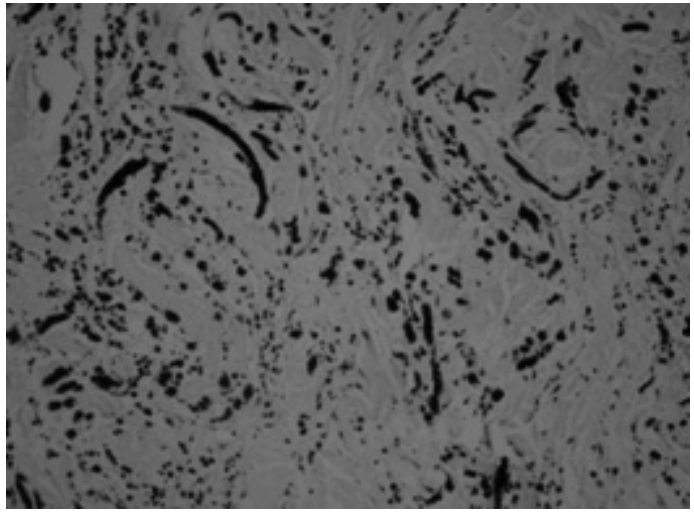

Sekil 4b. Elastik Von Gieson histokimyasal boyası ile tariflenen dejenere elastik fibriller ve sferik yapılarda siyah boyanma paterni( Elastik Von Gieson x200).

İzlem sonrası 12. ayda yapılan kontrolde hasta, yakınmalarının tamamen ortadan kalktığgnı ve günlük yaşamını sorunsuz olarak devam ettirdiğini belirtti.

\section{TARTIŞMA}

Elastofibroma dorsi, kollajen dokunun ender görülen, benign bir tümörü olup, skapula arkasında derin yerleşimli, sınırları tam ayırt edilemeyen, skapulayı dışa doğru iten, yumuşak doku kitlesi olarak tanımlanır (17). 
Patogenezi açıklamaya çalışan birçok görüş vardır. Bunlardan ilki, skapulanın alt ucunun toraks duvarına sürtünmesiyle subskapular bölgede oluşan yineleyen minör travmalardır ${ }^{(17,18)}$. Sıklıkla baskın kullanılan sağ tarafta ve ağır işlerde calışan kişilerde rastlanmasından dolayı, elastofibroma dorsi gelişimine travmanın neden olabileceği vurgulanmıştır (9). Diğer görüşler arasında, reaktif fibromatosis, vasküler yetersizliğe bağlı dejenerasyon, elastotik dejenerasyon, enzim defekti ve sistemik tutulum vardır $(6,8,19,20)$. Yapılan bir çalışmada 170 hastanın incelenmesinde olguların \% 32'sinde aile öyküsü saptanmış ve genetik yatkınlık olabileceği bildirilmiştir. McComb ve ark. (21) elastofibromada sitogenetik inceleme yaparak 1 numaralı kromozomda genetik instabilite artışı gözlemişler, bu klonal anormalliklere dayanarak lezyonun reaktiften daha çok neoplastik kökenli olduğunu belirtmiştir. Olguların \% 90'ında tek taraflı tutulum vardir $(22,23)$. Kadınlarda erkeklere oranla 8-13 kat fazla görüldüğü bildirilmişse de, bu sıklığın nedeni belirtilmemiştir $(17,24)$. Bir çalışmada olguların $\%$ 80'inin erkek olduğu bildirilmiştir (5).

Lezyonun sıklıkla 55 yaşın üzerinde görüldüğü bildirilmiştir (25), bu çalışmadaki olgu da 55 yaşında idi. İki taraflı tutulumun \% 10 oranında olduğu ortaya konulmuştur $(10,26,27)$. İki taraflı tutulumu olan kadın hastamızın aile öyküsü yoktu. Bu bulgular, etiyolojik açıdan travma dişında diğer etkenlerin de rol oynayabileceğini göstermektedir.

Elastofibromun tipik yerleşim yeri skapula alt köşesidir. Ayrıca, aksilla, mediasten, mide, inguinal bölge ve ayak gibi yerlerde atipik yerleşim gösterebilir. Olgumuzda kitle tipik yerleşim yerinde idi. Elastofibroma dorsi bulunan hastaların yarısında klinik belirti bulunmamaktadır ${ }^{(4,8,13)}$. Kitle zaman içinde, hastalarda sırt ve omuza vuran ağrı, omuz hareketleri sırasında atlama hissi ile kendini gösterir ve uzanırken sırtta şişlik hissedilebilir hale gelir. Omuza yayılan ağrı farklı tanı ve tedavilere yol açabilir. Majo ve ark. (4), inceledikleri 10 hastanın üçünün daha önce sıkışma sendromu tanısıyla başarısız bir tedavi gördüğünü, altı hastada ise sırt- ta ağrılı atlama nedeniyle cerrahi tedavi öncesinde fizyoterapi ve steroid enjeksiyonu uygulandığını; kitlenin ancak cerrahi çıkarımı sonrasında yakınmaların geçtiğini bildirmiştir.

Skapulotorasik hareketler sırasında skapulanın, kitlenin üzerinden atlaması ile ağrı oluşur. Oluşan bu atlama, toraks kavitesi tarafından kuvvetlendirilerek, duyulur bir ses haline dönüşür (28). Bu durumun diğer etiyolojik nedenleri arasında skapula altında osteokondrom, kötü kaynamış kot veya skapula, sinir yaralanmasına bağlı gelişen kas atrofisi sonucu skapula ile kotlar arasındaki dokuların incelmesi ve skapula cevresindeki bursal yapıların enflamasyonu sayılabilir (29). İleri yaştaki bir kadın hastada tipik yerleşim ve iki taraflı tutulum varlığ öncelikli öntanı olarak elastofibroma dorsiyi düşündürebilir.

Fizik muayenede kitle, hastanın yapacağı omuz fleksiyonu ve adduksiyon hareketiyle görünür hale gelir. En önemli radyolojik değerlendirme yöntemi MRI'dır (9,15). Malghem ve ark. (15), MRI incelemesinde kitle içindeki fibroz dokuların çevre kas dokuları ile benzer sinyal özelliği gösterirken, yağ dokunun kitleye göre daha yüksek sinyal özelliği gösterdiğini, bu bulguların kitle için patognomik olduğunu belirtmiştir. Solivetti ve ark. (30), ise tanı amaçlı USG kullanımının yeterli ve ucuz bir yöntem olduğunu bildirmiştir. Kransdorf ve ark. (31), radyolojik olarak MRI veya BT ile değerlendirmenin, histopatolojik değerlendirmeyle uyumlu olduğunu bildirmiştir. Ayırıcı tanıda lipoma, hemanjiyoma, metastatik veya primer sarkom, desmoid tümör, subskapular bursanın belirgin olması, nörofibroma, skatrisyel fibroma, fibrözhistiositoma, fibromatosis, fibrolipoma değerlendirilir. Tanıyı kesinleştirmek için iğne aspirasyonu veya insizyonel biyopsi yapılabilir; ancak eksizyonel biyopsi tercih edilmelidir $(6,8,10,20,32)$. Klinik muayene ve radyolojik değerlendirmenin yeterli olduğunu düşündüğümüzden dolayı hastamıza tanı amaçlı biyopsi uygulamadık.

Elastofibroma dorsinin tedavisinde, birçok yazar 
tarafından, yakınması olan hastalarda marjinal sınırlarda kitlenin çıkartılmasının yeterli olduğu belirtilmiştir ${ }^{(2-5,8,10)}$. Bu olguda da marjinal eksizyon uygulanmıştır. Cerrahi tedavi sonrası karşılaşılan en sık sorun hematom veya seroma oluşmasıdır $(1,2,5)$. Geniş bir alanda yapışık olan kitlenin çıkarımı sonrasında dikkatli bir kanama kontrolü yapılması ve kolun istirahata alınması önerilmiştir (1).

Sonuç olarak, elastofibroma dorsi, orta yaş hastalarda skapula alt köşesinde görülen iyi huylu bir tümördür. Klinik olarak az rastlandığı için, omuzla ilgili yakınmalarda tanıda akla getirilmelidir. Klinik ve radyolojik değerlendirme tanı için yeterlidir. Yakınmaları olan hastalarda, tümörü marjinal sınırlarda çıkarmak tedavi için yeterli olmaktadır.

\section{KAYNAKLAR}

1. Daigeler A, Vogt PM, Busch K, Pennekamp W, Weyhe D, Lehnhardt M, et al. Elastofibroma dorsi-differential diagnosis in chest wall tumours. World J Surg Oncol 2007:5:15.

http://dx.doi.org/10.1186/1477-7819-5-15 PMid:17280612 PMCid:1797045

2. Muramatsu K, Ihara K, Hashimoto T, Seto S, Taguchi T. Elastofibroma dorsi: diagnosis and treatment. $J$ Shoulder Elbow Surg 2007;16:591-595.

http://dx.doi.org/10.1016/j.jse.2006.12.010 PMid:17560807

3. Haney TC. Subscapular elastofibroma in a young pitcher: acase report. Am J Sports Med 1990;18:642-644. http://dx.doi.org/10.1177/036354659001800615 PMid:2285094

4. Majo J, Gracia I, Doncel A, Valera M, Nunez A, Guix M. Elastofibroma dorsi as a cause of shoulder pain or snappingscapula. Clin Orthop Relat Res 2001;(388):200204.

5. Chandrasekar CR, Grimer RJ, Carter SR, Tillman RM, Abudu A, Davies AM, et al. Elastofibroma dorsi: an uncommon benign pseudotumour. Sarcoma 2008; 2008:Article ID 756565, 4 pages.

6. Guha AR, Raja RC, Devadoss VG. Elastofibroma dorsia case report and review of literature. Int J Clin Pract 2004;58:218-220. http://dx.doi.org/10.1111/j.1368-5031.2004.0051.x PMid:15055873

7. Chang CC, Wu MM, Chao C, Lin SS, Liu JT, Lee JK, et al. Prevalence study of elastofibroma dorsi with retrospective evaluation of computed tomograpy. Chin J Radiol 2003;28:367-371.

8. Briccoli A, Casadei R, Di Renzo M, Favale L, Bacchini P, Bertoni F. Elastofibroma dorsi. Surg Today 2000;30:147-152.

http://dx.doi.org/10.1007/PL00010063

PMid:10664338
9. Naylor MF, Nascimento AG, Sherrick AD, McLeod RA. Elastofibroma dorsi: radiologic findings in 12 patients. AJR Am J Roentgenol 1996;167:683-637. PMid:8751681

10. Kara M, Dikmen E, Kara SA, Atasoy P. Bilateral elastofibromadorsi: proper positioning for an accurate diagnosis. Eur J Cardiothorac Surg 2002;22:839-841. http://dx.doi.org/10.1016/S1010-7940(02)00475-X

11. De Nictolis M, Goteri G, Campanati G, Prat J. Elastofibrolipoma of the mediastinum. A previously undescribed benign tumor containing abnormal elastic fibers. Am J Surg Pathol 1995;19:364-367. http://dx.doi.org/10.1097/00000478-199503000-00015 PMid:7872435

12. Giebel GD, Bierhoff E, Vogel J. Elastofibroma and preelastofibroma-a biopsy and autopsy study. Eur J Surg Oncol 1996;22:93-96. http://dx.doi.org/10.1016/S0748-7983(96)91781-3

13. Oueslati S, Douira-Khomsi W, Bouaziz MC, Zaouia K. Elastofibroma dorsi: A report on 6 cases. Acta Orthop Belg 2006;72:237-242. PMid:16768275

14. Massengill AD, Sundaram M, Kathol MH, el-Khoury GY, Buckwalter JH, Wade TP. Elastofibroma dorsi: a radiological diagnosis. Skeletal Radiol 1993;22:121-123. http://dx.doi.org/10.1007/BF00197991 PMid:8438182

15. Malghem J, Baudrez V, Lecouvet F, Lebon C, Maldague B, Vande Berg B. Imaging study findings in elastofibromadorsi. Joint Bone Spine 2004;71:536-541. http://dx.doi.org/10.1016/j.jbspin.2004.04.006 PMid: 15589435

16. Domanski HA, Carlen B, Sloth M, Rydholm A. Elastofibroma dorsi has distinct cytomorphologic features, making diagnostic surgical biopsy unnecessary: cytomorphologic study with clinical, radiologic, and electron microscopic correlations. Diagn Cytopathol 2003;29:327-333. http://dx.doi.org/10.1002/dc.10381 PMid:14648789

17. Greenberg JA, Lockwood RC. Elastofibroma dorsi. A case report and review of the literature. Orthop Rev 1989;18:329-333 PMid:2652048

18. Bennett KG, Organ CH Jr, Cook S, Pitha J. Bilateral elastofibroma dorsi. Surgery 1988;103:605-607. PMid:3283985

19. Alberghini M, Bacchini P, Pignatti G, Maltarello MC, Zanella L, Maraldi NM, et al. Histochemical and ultrastructural study of an elastofibroma dorsi coexistingwith a high grade spindle cell sarcoma. Eur J Histochem 2004;48(2):173-178. PMid: 15208086

20. Nagamine $\mathbf{N}$, Nohara $\mathbf{Y}$, Ito E. Elastofibroma in Okinawa. A clinicopathologic study of 170 cases. Cancer 1982;50:1794-1805. http://dx.doi.org/10.1002/1097-0142(19821101)50:9< 1794::AID-CNCR2820500925>3.0.CO;2-L

21. McComb EN, Feely MG, Neff JR, Johansson SL, Nelson M, Bridge JA. Cytogenetic instability, predominantly involving chromosome 1, is characteristic of elastofibroma. Cancer Genet Cytogenet 2001;126:68-72. http://dx.doi.org/10.1016/S0165-4608(00)00395-2

22. Nakamura Y, Ohta Y, Itoh S, Haratake A, Nakano Y, 
Umeda A, et al. Elastofibroma dorsi. Cytologic, histologic, immunohistochemical and ultrastructural studies. Acta Cytol 1992;36:559-562.

PMid:1636353

23. Hoffman JK, Klein MH, McInerney VK. Bilateral elastofibroma: a case report and review of the literature. Clin Orthop Relat Res 1996;325:245-250. http://dx.doi.org/10.1097/00003086-199604000-00030 PMid:8998883

24. Brandser EA, Goree JC, El-Khoury GY. Elastofibroma dorsi: prevalence in an elderly patient population as revealed by CT. AJR Am J Roentgenol 1998;171:977-980. PMid:9762978

25. Enzinger FM, Weiss SW, editors. Benign lipomatouos tumors. In: Soft tissue tumors. 3rd ed. St. Louis: Mosby, 1995, p:187-191.

26. Jarvi OH, Lansimies $\mathbf{P H}$. Subclinical elastofibromas in thescapular region in an autopsy series. Acta Pathol Microbiol Scand A 1975;83:87-108.

27. Kılıc D, Şahin E, Fındıkcıoğlu A, Bal N, Tercan F, Hatipoğlu A. Bilateral elastofibroma dorsi. Turk Toraks Dergisi 2007;8:52-54.
28. Percy EC, Birbrager D, Pitt MJ. Snapping scapula: a review of the literature and presentation of 14 patients. Can J Surg 1988;31:248-250. PMid:3292030

29. Manske RC, Reiman MP, Stovak ML. Nonoperative and operative management of snapping scapula. Am J Sports Med 2004;32:1554-1565. http://dx.doi.org/10.1177/0363546504268790 PMid:15310586

30. Solivetti FM, Bacaro D, Di Luca Sidozzi A, Cecconi P. Elastofibroma dorsi: ultrasound pattern in three patients. $J$ Exp Clin Cancer Res 2003;22:565-569. PMid: 15053298

31. Kransdorf MJ, Meis JM, Montgomery E. Elastofibroma: MR and CT appearance with radiologicpathologic correlation. AJR Am J Roentgenol 1992;159:575-579. PMid: 1503030

32. Marin ML, Perzin KH, Markowitz AM. Elastofibroma dorsi: benign chest wall tumor. J Thorac Cardiovasc Surg 1989;98:234-238.

PMid:2755156 